\title{
Transmission Congestion Management and Techno Economical Analysis using Placement of TCSC
}

\author{
Pallavi Choudekar, Sanjay Sinha, Divya Asija, Ruchira, Anwar Siddiqui
}

\begin{abstract}
Congestion management is a major problem in deregulated power system. Congestion leads to increase in transmission line loading, increases losses and reducing transmission efficiency. It also leads to increase in congestion cost and thus affects technical as well as economical parameters. Research work is carried out under single line critical contingency condition. Critical contingency is found out by overall performance index (OPI). Optimal Power Flow (OPF) is carried out and objective is to maximize social welfare. Thyristor controlled series compensator is used to improve power flow, thus it reduces congestion and improves techno-economical parameters. Optimal location of Thyristor controlled series compensator (TCSC) is found out by LMP difference method.
\end{abstract}

Index Terms: Critical Contingency, Optimal Power Flow, Locational Marginal Price.

\section{INTRODUCTION}

Managing congestion of transmission line is major problem in restructured power system. Congestion occurs as capacity of transmission line is limited and as load demand increases, generators produce more output and hence transmission lines are carrying more power than its rated capacity. Price of energy in congested area is more than non-congested area and hence market efficiency decreases thus consumers have to pay more. For managing congestion of the transmission line, two methods are used by Independent System Operator (ISO). Technical / cost free method: In this method removal of most congested transmission lines, use of transformer taps and use of FACTS devices are employed.

Non-technical / Non cost free: Various techniques like optimal dispatch of generator output and load shedding techniques are used.

\section{Literature review}

Different methods of congestion management have been studied by researchers. Authors have demonstrated placement of TCSC for reducing congestion under (N-1) contingency condition and optimal location of TCSC is found out by GA and PSO [1]. Finding critical contingency is an important issue and this single line critical contingency analysis is done by finding out performance index [2]. New approaches are used such as PSO, DE and composite differential algorithm and performance of these algorithms are compared, use of TCSC, SVC and TCPST is done to improve loadability of deregulated power system [3].Recently placement of multiple FACTS devices for increasing social welfare is done by considering annual cost of FACTS devices, operational cost and benefit of consumers [4]. Self-adaptive firefly algorithm is used to fulfill multi-objectives such as minimization of real power loss, voltage profile improvement using multi type FACTS devices such as TCSC, SVC and UPFC [5]. Cost of installation of FACTS is a major issue, placement of multiple type FACTS devices with minimum cost of installation is done to improve loadability of power system. Optimal location is found using PSO [6]. Authors introduced the concept of techno-economical congestion management by optimal placement of SVC and results were illustrated in [7]. Interline power flow controller (IPFC) showed effective solution for power flow improvement [8]. Concept of VSC-OPF is introduced and is carried out in contingency condition and placement of FACTS devices for improving power flow [9]. Bacterial swarming algorithm is used for optimal location of FACTS devices to improve system load ability and reduce generation cost; four different types of FACTS devices are included in OPF problem [10]. Intelligent algorithm like GA based fuzzy are used for multi-objective optimization for placement of TCSC and SVC for controlling congestion in transmission network [11].Optimal power flow using differential evolution and hybrid PSO is carried out and placement of TCSC, TCPS(Thyristor Controlled Phase Shifter) has been done to improve power flow [12][13] Authors used Non dominated Sorting Particle Swarm Optimization (NSPSO) is used for optimal location of TCSC and SVC under N-1 contingency state for multi- objective optimization [14]. Placement of SVC in normal and contingency for improving voltage stability is discussed [15].

\section{Contribution of Research Work}

Techno-Economic analysis during severe contingency state using TCSC is the key feature of this work. The objective of the work is to maximize social welfare function during severe contingency and maintain power system security. OPF based optimization is done to find out operating cost.

\section{Paper layout}

Research paper is organized in 5 sections. Section $I$ is

Revised Manuscript Received on 02 July, 2019

Pallavi Choudekar, Amity University Uttar Pradesh, India.

Sanjay Sinha, Amity University Uttar Pradesh, India.

Divya Asija, Amity University Uttar Pradesh, India

Ruchira, Amity University Uttar Pradesh, India

Anwar Siddiqui, Jamia Milia Islamia, New Delhi, India 
introduction and it highlights main contributions of the research work. In section II is modeling of TCSC has been done. Problem formulation and objective to maximize social welfare function have been discussed in section III. Section IV illustrates the results and discussion, finding severe contingency, best location of TCSC for placement in severe contingency and analysis of several techno-economic parameters. Conclusions from the analysis done are mentioned in section $\mathrm{V}$.

\section{MODELLING OF THYRISTOR CONTROLLED SERIES COMPENSATORS (TCSC)}

TCSC consists of series capacitor bank in parallel with thyristor-controlled reactor (TCR), which is connected for providing smooth variation in series capacitive reactance $\left(\mathrm{X}_{\text {cap }}\right)$ as shown in Fig.1.

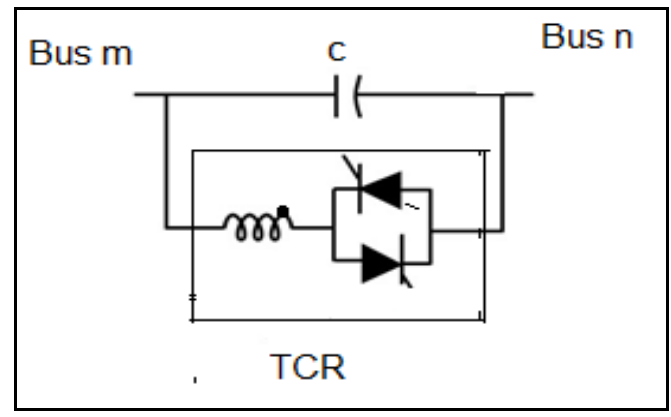

Fig.1 Model of TCSC

Reactance of TCSC depends on transmission line reactance and compensation ratio of TCSC

$$
\begin{aligned}
& \mathrm{X}_{\mathrm{mn}}=\mathrm{X}_{\mathrm{L}}+\mathrm{X}_{\mathrm{TCSC}} \\
& \mathrm{X}_{\mathrm{TCSC}}=\alpha_{\mathrm{TCSC}}{ }^{*} \mathrm{X}_{\mathrm{L}} \\
& -0.8 \leq \alpha_{T C S C}{ }^{K} \leq 0.2
\end{aligned}
$$

\section{Problem Formulation}

Social Benefit_Maximization

Optimal power flow is used for management of congestion in deregulated power market. Objective function used is to maximize social welfare function which is affected due to congestion in the network. Nonlinear and constrained optimization approach has been used. Problem has a scalar objective and constraints which are equality and inequality constraints.

Social benefit

Min: $=-\left[\sum \mathrm{C}_{\text {Demi }}\left(\mathrm{P}_{\text {Demi }}\right)-\sum \mathrm{C}_{\text {supplyi }}\left(\mathrm{P}_{\text {supplyi }}\right)\right]$

Consumer benefit function

$\mathrm{C}_{\text {Dem i }} \mathrm{P}_{\text {Dem } \mathrm{i}}=\mathrm{X}_{\text {Dem } \mathrm{i}}+\mathrm{Y}_{\text {Dem i }} \mathrm{P}_{\text {Dem } \mathrm{i}}+\mathrm{Z}_{\text {Dem i }}\left(\mathrm{P}_{\text {Dem } \mathrm{i}}\right)^{2}$

Supplier offer function

$$
\mathrm{C}_{\text {supplyi }} \mathrm{P}_{\text {supplyi }}=\mathrm{X}_{\text {supplyi }}+\mathrm{Y}_{\text {supplyi }} \mathrm{P}_{\text {supplyi }}+\mathrm{Z}_{\text {supplyi }}\left(\mathrm{P}_{\text {supplyi }}\right)^{2}
$$

Subject to

Power flow equation

$\mathrm{F}\left(\delta, \mathrm{V}, \mathrm{Q}_{\mathrm{g}}, \mathrm{P}_{\text {supply }}, \mathrm{P}_{\text {Dem }}\right)=0$
Supply bid

$\mathrm{O} \leq P_{\text {Supply }} \leq \mathrm{P}_{\text {supply max }}$

Demand bid

$0 \leq P_{\text {Dem }} \leq P_{\text {Dem } \max }$

Limits on power transfer are

$\mathrm{P}_{\mathrm{mn}}(\delta, \mathrm{V}) \leq \mathrm{P}_{\text {mnmax }}$

$\mathrm{P}_{\mathrm{nm}}(\delta, \mathrm{V}) \leq \mathrm{P}_{\mathrm{nm} \max }$

Generator reactive power limit

$Q_{g \text { min }} \leq Q_{g} \leq Q_{g \text { max }}$

Voltage limits

$V_{\text {min }} \leq V \leq V_{\max }$

Where,

$\mathrm{C}_{\text {supply }}$ represents cost of Supply ( $\$$ / MWh )

$\mathrm{C}_{\mathrm{dem}} \quad$ represents cost of demand ( $\$ / \mathrm{MWh}$ )

$\mathrm{V}$ and $\delta$ are voltage and phase angle at a bus.

$\mathrm{P}_{\mathrm{mn}}$ and $\mathrm{P}_{\mathrm{nm} \text { are }}$ bidirectional power flow in transmission line.

Congestion management problem has been solved using the above stated problem formulation with the objective of maximization of social welfare. Optimal power flow is carried out and LMP at all buses are found. Various technical parameters like loading of each transmission line and voltage at each bus is improved also there is improvement in social welfare by use of optimal placement of TCSC.

\section{RESULTS AND DISCUSSION}

IEEE 14 bus test system is used for simulation which is shown in Fig. 2. Total real power generation of the system is 272.4 MW and reactive power generation is 78.5 MVAR. Total real power demand is $259.3 \mathrm{MW}$ and reactive power demand is 73.6 MVAR.

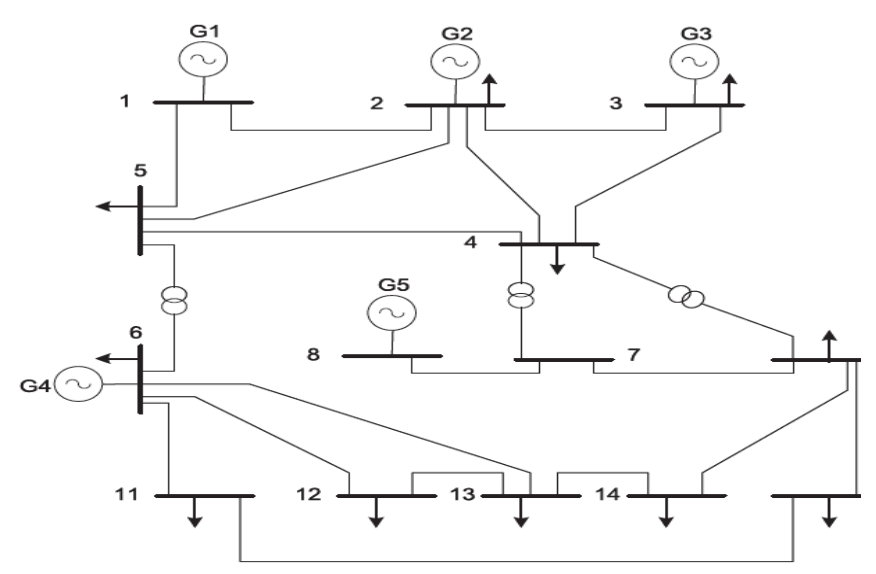

Fig. 2 IEEE 14 bus system

Optimal power flow is carried out under severe N-1 contingency condition and 
location of TCSC is found out as per LMP difference. Placement of TCSC is done to improve techno-economic aspects of congestion.

\section{Ranking of Severe N-1 Contingency}

Planning and operation of power system is based on $\mathrm{N}-1$ security criterion, that is power system should remain in secured condition under all first contingencies.

Single line (N-1) contingency is created in IEEE 14 bus system and performance index is calculated to find most severe contingency. Higher value of performance index indicates most severe is the contingency.

Performance index (PI) has two components.

Active Power Performance Index $\left(\mathrm{PI}_{\mathrm{P}}\right)$-for determining line overloading

$\mathrm{PI}_{\mathrm{P}}=\sum_{l=1}^{N_{L}}(\mathrm{~W} / 2 \mathrm{n})\left(\mathrm{P}_{\mathrm{L}} / \mathrm{P}_{\mathrm{L}}{ }^{\max }\right)^{2 \mathrm{n}}$

Where,

$\mathrm{P}_{\mathrm{L}}=$ Power flow through line $L$

$\mathrm{P}_{\mathrm{L}}{ }^{\max }=$ Rated capacity of transmission line $L=\left(\mathrm{V}_{\mathrm{m}} / \mathrm{V}_{\mathrm{n}}\right) / \mathrm{X}$

$\mathrm{N}_{L}=$ Total number of transmission lines

$\mathrm{W}=$ Weighting factor $=1$

$\mathrm{n}=$ Penalty function $=1$

$\mathrm{V}_{\mathrm{m}}=$ Voltage at bus $\mathrm{m}$

$\mathrm{V}_{\mathrm{n}}=$ Voltage at bus $\mathrm{n}$

$\mathrm{X}=$ Reactance of transmission line connected between bus $\mathrm{m}$ and bus $n$.

Voltage Performance Index_( $\left.\mathrm{PI}_{\mathrm{V}}\right)$ - for the determination of bus voltage violations.

$\mathrm{PI}_{\mathrm{V}}=\sum_{m=1}^{N_{b}}(\mathrm{~W} / 2 \mathrm{n})\left[\left(\left|V_{m}\right|-\left|V_{m}^{s p}\right|\right) / \Delta \mathrm{V}_{m}^{\lim }\right]^{2 n}$

$\left|V_{m}\right|=$ Magnitude of voltage at bus $\mathrm{m}$

$\left|V_{m}^{s p}\right|=$ Magnitude of voltage specified at bus $\mathrm{m}$

$\Delta \mathrm{V}_{m}^{\lim }=$ Voltage violation limit

$\mathrm{n}=$ Penalty function

$\mathrm{N}_{\mathrm{b}}=$ Total number of buses

$\mathrm{W}=$ Real non negative weighting factor $=1$

Overall Performance index $(\mathrm{OPI})=\mathrm{PI}_{\mathrm{P}}+\mathrm{PI}_{\mathrm{V}}$

Transmission line outage is done, for each case load flow is carried out using Newton Raphson method. Overall performance index is calculated using results of load flow. OPI is arranged in descending order and severe contingency is determined.

Table 1. Overall Performance Index (OPI)

\begin{tabular}{|c|c|c|c|c|c|}
\hline $\begin{array}{l}\text { Bus } \\
\text { No. }\end{array}$ & $\begin{array}{l}\text { Bus } \\
\text { No. }\end{array}$ & $\begin{array}{l}\text { Line } \\
\text { outage }\end{array}$ & PIp & PIv & OPI \\
\hline 6 & 11 & 8 & 8.34062 & $\begin{array}{r}45.6542 \\
5\end{array}$ & $\begin{array}{r}53.9948 \\
8\end{array}$ \\
\hline 10 & 11 & 14 & 7.90206 & $\begin{array}{r}23.4008 \\
6\end{array}$ & $\begin{array}{r}31.3029 \\
3\end{array}$ \\
\hline 9 & 10 & 12 & $\begin{array}{r}15.7597 \\
1\end{array}$ & $\begin{array}{r}9.25232 \\
2\end{array}$ & $\begin{array}{r}25.0120 \\
3\end{array}$ \\
\hline 7 & 9 & 11 & $\begin{array}{r}14.9465 \\
4\end{array}$ & $\begin{array}{r}8.52864 \\
8\end{array}$ & $\begin{array}{r}23.4751 \\
9\end{array}$ \\
\hline 4 & 5 & 7 & $\begin{array}{r}12.1319 \\
5\end{array}$ & $\begin{array}{r}5.56614 \\
2\end{array}$ & $\begin{array}{r}17.6980 \\
9\end{array}$ \\
\hline 1 & 2 & 1 & $\begin{array}{r}11.9661 \\
5\end{array}$ & $\begin{array}{r}5.14420 \\
7\end{array}$ & $\begin{array}{r}17.1103 \\
6\end{array}$ \\
\hline 6 & 13 & 10 & $\begin{array}{r}11.9498 \\
6\end{array}$ & $\begin{array}{r}5.05394 \\
9\end{array}$ & $\begin{array}{r}17.0038 \\
1\end{array}$ \\
\hline 13 & 14 & 16 & $\begin{array}{r}11.2996 \\
6\end{array}$ & $\begin{array}{r}5.64968 \\
9\end{array}$ & $\begin{array}{r}16.9493 \\
5\end{array}$ \\
\hline 1 & 5 & 2 & $\begin{array}{r}11.8021 \\
6\end{array}$ & 5.06687 & $\begin{array}{r}16.8690 \\
3\end{array}$ \\
\hline 2 & 3 & 3 & $\begin{array}{r}11.6367 \\
1\end{array}$ & 5.17993 & $\begin{array}{r}16.8166 \\
4\end{array}$ \\
\hline 2 & 4 & 4 & $\begin{array}{r}11.5023 \\
1\end{array}$ & $\begin{array}{r}5.17038 \\
2\end{array}$ & $\begin{array}{r}16.6726 \\
9\end{array}$ \\
\hline 9 & 14 & 13 & $\begin{array}{r}11.4903 \\
2\end{array}$ & $\begin{array}{r}5.03389 \\
4\end{array}$ & $\begin{array}{r}16.5242 \\
2\end{array}$ \\
\hline 6 & 12 & 9 & $\begin{array}{r}11.5642 \\
1\end{array}$ & $\begin{array}{r}4.90999 \\
1\end{array}$ & 16.4742 \\
\hline 2 & 5 & 5 & 11.2733 & $\begin{array}{r}5.09917 \\
6\end{array}$ & $\begin{array}{r}16.3724 \\
8\end{array}$ \\
\hline 3 & 4 & 6 & $\begin{array}{r}11.1922 \\
8\end{array}$ & $\begin{array}{r}5.17667 \\
6\end{array}$ & $\begin{array}{r}16.3689 \\
5\end{array}$ \\
\hline 12 & 13 & 15 & $\begin{array}{r}11.0973 \\
6 \\
\end{array}$ & $\begin{array}{r}5.25012 \\
7 \\
\end{array}$ & $\begin{array}{r}16.3474 \\
8\end{array}$ \\
\hline
\end{tabular}

From Table 1, severe contingency is outage of line 8 which is connected between bus 6 and bus 11 . Under this contingency condition it is observed that, three lines $(10,11$ and 12) get congested. By appropriate placement of TCSC, congestion of these lines can be managed.

\section{Optimal location of TCSC based on LMP difference}

Locational Marginal Price (LMP) varies at various bus locations due to congestion of transmission line and losses in power network. LMP considers supply bids, offers of demand, characteristics of transmission line and constraints imposed on transmission line.

LMP at bus $m \rho_{\mathrm{m}}=\lambda+\lambda_{\mathrm{L}, \mathrm{m}}+\lambda_{\mathrm{C}, \mathrm{m}}$

LMP at bus $\mathrm{m} \rho_{\mathrm{n}}=\lambda+\lambda_{\mathrm{L}, \mathrm{n}}+\lambda_{\mathrm{C}, \mathrm{n}}$

Where,

$\lambda$ is generator marginal cost ( $\$ / \mathrm{MWh})$

$\lambda_{\mathrm{L}, \mathrm{m}}$ is marginal losses cost at bus $\mathrm{m}(\$ / \mathrm{MWh})$

$\lambda_{\mathrm{C}, \mathrm{m}}$ is congestion cost at bus $\mathrm{m}(\$ / \mathrm{MWh})$

$\lambda_{\mathrm{L}, \mathrm{n}}$ is marginal losses cost at bus $\mathrm{n}(\$ / \mathrm{MWh})$

$\lambda_{\mathrm{C}, \mathrm{n}}$ is congestion cost at bus $\mathrm{n}(\$ / \mathrm{MWh})$

LMP difference occurs when there is congestion in the transmission line connected between two buses. Congested network does not allow transmission of power to load from generators which has fewer prices. High cost generator therefore will serve the load 
and that will lead to increase in the market price. More LMP difference means that particular line is congested and thus increase congestion cost. TCSC is placed in that line to reduce congestion.

LMP difference between bus $\mathrm{m}$ and bus $\mathrm{n} \Delta \rho_{\mathrm{mn}}=\left(\lambda_{\mathrm{L}, \mathrm{m}}+\lambda_{\mathrm{C}, \mathrm{m}}\right.$ )$-\left(\lambda_{\mathrm{L}, \mathrm{n}}+\lambda_{\mathrm{C}, \mathrm{n}}\right) \quad(18)$

LMP difference is calculated from LMPs and it has been found that LMP difference is highest for line connected between buses $9-10$; this is possible location for TCSC placement for redistributing line flow and reduce overloading.

\section{Placement of TCSC for Improving Techno- Economic Parameters during Congestion}

Severe contingency and optimal location of FACTS devices have been found. Severe contingency is outage of line 8 (line connected between bus 6 and bus 11) When line 8 is removed, number of overloaded lines is 3 and number of voltage violation buses are 2 , so the performance index is also equal to addition of number of overloaded lines and number of voltage violation buses. Performance index is highest when line 8 is removed. Three lines gets congested it results in reduction of transmission line efficiency. Voltage stability is also affected because of increase in losses. TCSC is placed at optimal location for improving power flow, transmission efficiency, voltage stability and social welfare maximization.

\section{Improving Percentage Loading of Transmission Line}

The effect on transmission line loading is observed after placement of TCSC. Percentage line loading is calculated from actual power flow and rated power flow through the line. TCSC has been placed in series with line (9-10).

Table 2 shows percentage loading of transmission lines under severe contingency state without TCSC and also when TCSC is placed in IEEE 14 bus system. There is reduction in line loading and congestion of overloaded lines is reduced.

Table 2. Percentage loading

\begin{tabular}{ccc} 
& \multicolumn{2}{c}{$\begin{array}{c}\text { Loading of Transmission lines under severe } \\
\text { contingency (\%) }\end{array}$} \\
\cline { 2 - 3 } Line No. & Without FACTS & $\begin{array}{c}\text { TCSC in series with } \\
\text { transmission line (9-10) }\end{array}$ \\
\hline Line no. 10 & 123 & 116 \\
Line no. 11 & 161 & 84 \\
Line no. 12 & 292 & 62 \\
\hline
\end{tabular}

\section{Voltage stability enhancement}

Power losses increase in congestion state and therefore voltage stability gets affected Voltage stability can be improved by connecting TCSC in the system under consideration. Voltage at all buses should not be violated; it should lie between 0.9 to $1.1 \mathrm{pu}$. Voltage at all buses are maintained within limits which can be observed from Fig 3.

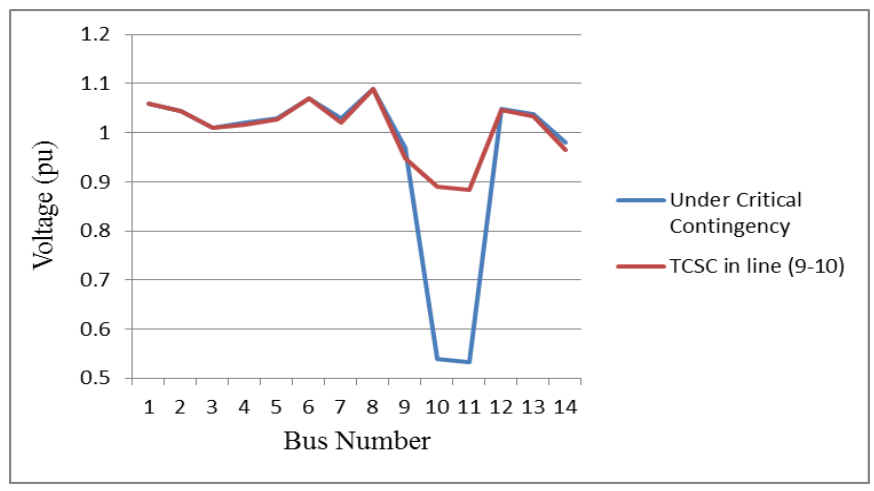

Fig 3. Voltage at all buses

\section{Improvement in Transmission Line Efficiency}

Due to congestion in the transmission line, transmission losses are more and therefore power transferred at the receiving end is less. When TCSC is connected in the IEEE 14 bus system, transmission losses are reduced by controlling power flow through transmission line so transmission efficiency gets enhanced. Fig.4 shows effect of placement TCSC on transmission line efficiency of line 12. Transmission efficiency of line 12 improves by $38.48 \%$.

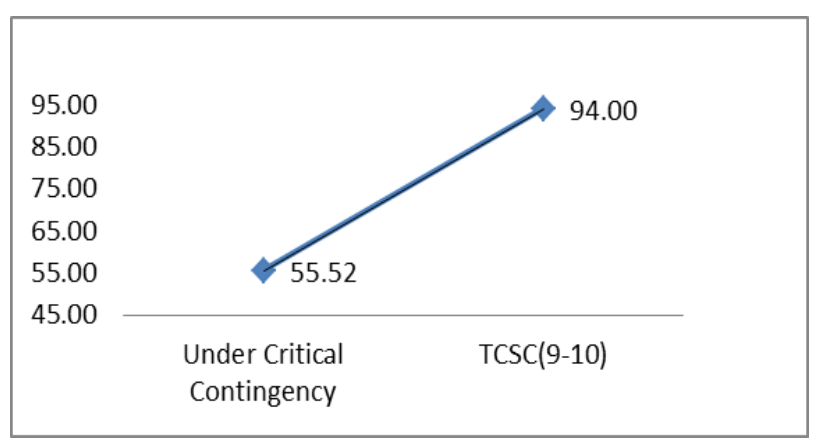

Fig 4. Transmission efficiency of line no. 12

\section{Maximization of Social Welfare}

Problem formulation in the research work is done with the objective of social welfare maximization. Social welfare maximization is achieved as clearly comprehended by Fig.5.

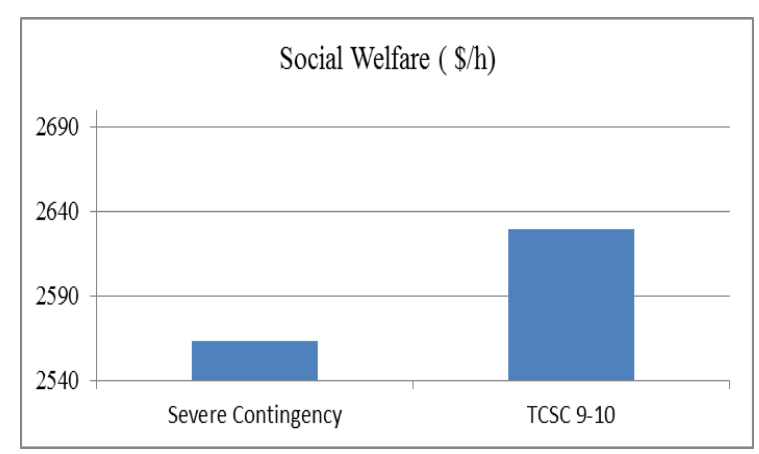

Fig.5. Social Welfare

\section{Conclusion}

Power system does not remain secure in single line 
contingency condition. Most severe contingency has been found out and problem of congestion is solved in that condition by placement of TCSC. Optimal power flow is used to solve this problem and improvement in line loading, transmission efficiency, voltage stability and social welfare is observed under most severe single line contingency condition.

\section{REFERENCES}

[1] I. Rashed, H. I. Shaheen, X. Z. Duan, and S. J. ChengEvolutionary optimization techniques for optimal location and parameter setting of TCSC under single line contingency. vol. 205, no. 1. Appl. Math. Comput., (2008) 133-147

[2] P. Sekhar and S. Mohanty.:Power system contingency ranking using Newton Raphson load flow method.Annual IEEE India Conference, INDICON (2013)

[3] S. Nagalakshmi and N. Kamaraj.:Comparison of computational intelligence algorithms for loadability enhancement of restructured power system with FACTS devices. vol. 5. Swarm Evol. Comput. (2012). 17-27

[4] A. Elmitwally and A. Eladl.: Planning of multi-type FACTS devices in restructured power systems with wind generation. vol. 77. Int. J. Electr. Power Energy Syst. (2016).33-42

[5] C. Asir Rajan C., M. Surya Kalavathi, and S. Ranganathan.: Self-adaptive firefly algorithm based multi-objectives for multi-type FACTS placement. vol. 10. no. 11. IET Gener. Transm. Distrib. (2016). 2576-2584

[6] M. Saravanan, S. M. R. Slochanal, P. Venkatesh, and J. P. S. Abraham.: Application of particle swarm optimization technique for optimal location of FACTS devices considering cost of installation and system loadability. vol. 77. no. 3-4. Electr. Power Syst. Res. (2007) 276-283

[7] F. B. Alhasawi and J. V. Milanovic.: Techno-Economic Contribution of FACTS Devices to the Operation of Power Systems With High Level of Wind Power Integration. vol. 27, no. 3. IEEE Trans. Power Syst. (2012). 1414-1421

[8] A. Mishra and G. V. N. Kumar.: Congestion management of deregulated power systems by optimal setting of Interline Power Flow Controller using Gravitational Search algorithm. vol. 118.J. Electr. Syst. Inf. Technol. (2016).1-15.

[9] J. Aghaei, M. Gitizadeh, and M. Kaji.: Placement and operation strategy of FACTS devices using optimal continuous power flow. vol. 19. no. 6. Sci. Iran. (2012.). 1683-1690,

[10]Z. Lu, M. S. Li, L. Jiang, and Q. H. Wu.: Optimal allocation of FACTS devices with multiple objectives achieved by Bacterial Swarming Algorithm. in IEEE Power and Energy Society 2008 General Meeting: Conversion and Delivery of Electrical Energy in the 21 st Century, PES. (2008)

[11] M. Gitizadeh and M. Kalantar.: Genetic algorithm-based fuzzy multi-objective approach to congestion management using FACTS devices. vol. 90. no. 8. Electr. Eng. (Archiv fur Elektrotechnik). (2009).539-549

[12] M. Basu.: Optimal power flow with FACTS devices using differential evolution..vol.30.no. 2. Int. J. Electr. Power Energy Syst. (2008). $150-156$

[13]E. Nanda Kumar and R. Dhanasekaran.: Optimal Power Flow with FACTS Controller Using Hybrid PSO. vol.39. no. 4. Arab. J. Sci. Eng. . (2014), 3137-3146

[14] R. Benabid, M. Boudour, and M. A. Abido.: Optimal location and setting of SVC and TCSC devices using non-dominated sorting particle swarm optimization. vol. 79. no. 12. Electr. Power Syst. Res. (2009).1668-1677

[15] Pallavi Choudekar, SK Sinha, Anwar Siddiqui: Optimal location of SVC for improvement in voltage stability of a

power system under normal and contingency condition. International Journal of System Assurance Engineering and Management.vol.8. Issue 2 (2017). 1312-1318.

\section{AUTHORS PROFILE}

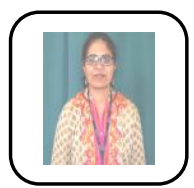

Pallavi Choudekar is currently pursuing Ph.D in Electrical Engineering from Amity University, Uttar Pradesh. She received her M. Tech from Gautam Buddha Technical University, Uttar Pradesh and B. E. from Pune University. She has teaching experience of 16 years During her academic career she held various key administrative positions

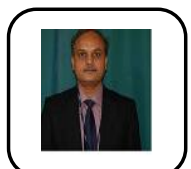

Dr. S.K. Sinha is professor, Electrical Engineering Department. Amity University, Uttar Pradesh, India. He received his B.Sc Engineering (Electrical) from M.I.T Muzzaffarpur, Bihar, M.Tech from RIT Jamshedpur (Now NIT Jamshedpur) and Ph.D. from IIT Roorkee with specialization in Power System. He has 18 years of teaching, research and industrial experience

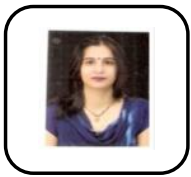

Divya Asija is currently pursuing Ph.D in Electrical Engineering from Amity University, Uttar Pradesh. She received her $M$. Tech from YMCA institute of Engineering Faridabad and B. E. from Apeejay College of Engineering, Sohna, Gurgaon. She has teaching experience of 11 years. During her academic career she held various key administrative positions. She has published several research papers in reputed international journals and conferences. Her professional interests include Congestion Management in Transmission System, Distributed Generation and other related field in power system.

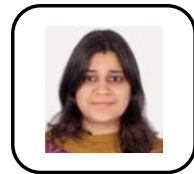

Ruchira received the M.E degree in Electrical Engineering from the PEC University of Technology, Chandigarh in 2009. She has around 9 years of teaching. Presently, she is working as an Assistant Professor in the department of Electrical and Electronics Engineering at Amity University, Uttar Pradesh. Her research interests include power system control and renewable energies.

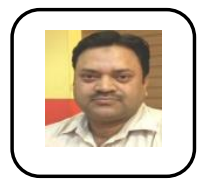

Dr. Anwar Siddiqui is a Professor in the Department of Electrical Engineering, Faculty of Engineering and Technology, Jamia Millia Islamia (JMI), and has 24 years of teaching and research experience in the field of Power systems Control and Management. He was a faculty member at Department of Electrical Engineering, Z.H. College of Engineering and Technology, AMU, Aligarh before joining Jamia. He also served at BITS, Pilani Dubai Campus as Associate Professor, Electrical \& Electronics Engineering and officiating Registrar during 2003 - 2008. Dr Siddiqui obtained his B. Tech. (Electrical Engineering) and M. Tech. (Power System \& Drives), both from Department of Electrical Engineering, Z.H. College of Engineering and Technology AMU, Aligarh with Honours. $\mathrm{He}$ earned his $\mathrm{PhD}$ degree in the field of Electrical Engineering from Department of Electrical Engineering, Faculty of Engineering and Technology, Jamia Millia Islamia in 2001.Dr. Anwar has done extensive research work in the broad area of Power System Control and Management, specifically on Congestion management in Deregulated Power System, FACTS Devices and Applications of Artificial

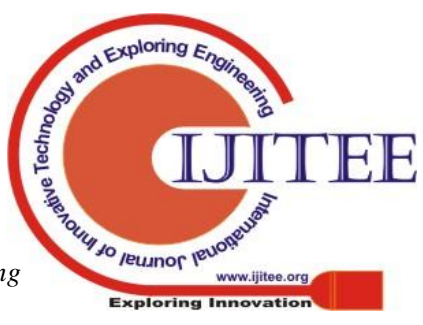


Intelligence Techniques in the field of Power System. He has published many research papers in International Journals and Conferences of repute. Currently his citation index is more than 200 with h-index 9 and i10-index 6. His current research impact factor is 17.45 . He is also reviewer of many reputed journals in his field. 